\title{
Is the Second Demographic Transition a useful concept for demography? Introduction to a debate
}

\section{Francesco C. Billari and Aart C. Liefbroer}

Is the Second Demographic Transition a useful concept for demography? As co-chairs of the Working Group on the Second Demographic Transition of the European Association for Population Studies (EAPS), we thought that time was due for a public debate, if possible animated and thought-provoking, between supporters and sceptics of the concept. Thanks to the approval and encouragement of the conference organising committees, we were able to organise the debate at the occasion of the European Population Conference 2003, during a mild August in Warsaw. Participants to the conference testified a remarkably high interest by packing a large meeting room and contributing to the lively debate with exclamations and applause, disagreement and interventions. As panellists we had invited two scholars whom we deemed among the sceptics, David Coleman and Giuseppe Micheli, and two scholars among the supporters, Eva Bernhardt and Dirk van de Kaa. In fact, as we all know, Dirk van de Kaa is more than a supporter, being, together with Ron Lesthaeghe, the first proponent of the idea of Second Demographic Transition. We asked the panellists to be as provocative as they could be. As we shall see, the dividing line between sceptics and supporters proved to be fuzzier than we originally had in mind.

Given the success of the debate, its extension to the scientific community beyond the participants to the Warsaw session seemed to be a natural choice. With great pleasure we thus introduce the initiative of the Vienna Institute for Demography to publish the concise versions of the contributions to the debate in the Vienna Yearbook for Population Research 2004.

As we mentioned in the mission statement of the Working Group, the concept of the "Second Demographic Transition" (2DT), introduced by Ron Lesthaeghe and Dirk van de Kaa in 1986, has profoundly influenced research on family and fertility behaviour. It can be argued that presently, it constitutes "the" mainstream concept among population scholars dealing with demographic change in European societies.

The 2DT entails on the one side a macro-level view of societal development that stresses the importance of ideational changes in bringing about certain demographic behaviours such as single living, pre- and post-marital cohabitation, delayed fertility, high prevalence of non-marital fertility and high rates of union disruption. This developmental view is subject to debate, in particular with regard to the possible persistence of the differences between the patterns of family and fertility behaviour in north-western Europe - the cradle of "new" family patterns-and southern European societies on the one side and central and eastern European countries on the other side. This debate has often been framed as whether family and fertility behav- 
iour will converge to a common "standard", as the one set by societies that are considered to be most advanced in the 2DT, i.e., the Scandinavian countries. On the other side, the 2DT concept has consequences for the micro-level as well by focussing attention on the importance of subjective evaluations (especially, of values) in shaping differential family and fertility behaviours within societies. This is of course connected to the macro-level developmental idea of 2DT (a higher share of the population sharing "new" values in certain countries may imply a higher share of the population exhibiting "new" behaviours), although it has a more general applicability. Long-term persistence of old behavioural patterns or resistance to new behaviours can be connected to the reproduction of certain values. In addition, the connection between values and behaviour may not be direct and may vary across contexts.

The contributions to the debate that follow are thought-provoking and their content has been entirely left to the authors' own willingness to be challenged on this topic, without a standard "homogenisation" with peer review. The papers reflect the fact that not every author can easily be classified as either supporter or sceptic. The positions of Van de Kaa and Coleman are more pronounced in this respect than those of Bernhardt and Micheli. Dirk van de Kaa provides a "simple and unqualified" positive answer on the usefulness of the Second Demographic Transition as a research concept. He recognises that the focus of the concept has changed, and that perhaps the term "revolution" would have better fit his vision of the concept. He also takes a defensive stand on sceptics who use empirical data with a falsifying mood, specifying that the value of the concept does not depend on empirical "deviations" from a fairly general pattern which in the end implies some convergence, and that one should not aim for a single demographic variable as a measure of the situation in terms of progression of the 2DT. David Coleman's "agnostic" comments are exactly matching Van de Kaa's claims. Coleman challenges the uniqueness of the 2DT, seeing it instead as a continuation of the First Demographic Transition, the demographic meaning of the term (maintaining a strict definition of the interests of demographers to be focused on "birth and death"), and most of all, the empirical validation of the 2DT outside northwestern Europe and several other countries such as the USA, Canada, Australia and New Zealand. The contributions by Eva Bernhardt and Giuseppe Micheli basically challenge our initial idea that Bernhardt would clearly appear as a "supporter" and Micheli as a "sceptic". In fact, Bernhardt, although seeing that the micro-level part of the 2DT idea with its emphasis on values has to be recognised as crucial, identifies what she sees as an important shortcoming of 2DT theory. The lack of an explicit gender perspective is indicated as the most problematic part in the 2DT by Bernhardt who also agrees with Van de Kaa's idea that the term "transition" is somehow a misnomer and should be replaced by "revolution". Micheli on the other side agrees with the general recognition of postmodernism as guiding present demographic change. He underlines that the 2DT is taking place within territorial cleavages that have existed in Europe for a long time, and that convergence is definitely not to be expected in the short term (thus somewhat agreeing with Van de Kaa). Micheli argues for the addition of a component in the decision-making process that 
emphasises the importance of value change: the "disposition to risk" that seems to be a necessary condition to trigger family and fertility within postmodern societies. But we better stop here and give the floor to the panellists themselves. 